\title{
USO DE METODOLOGIAS ATIVAS NA FORMAÇÃO CONTINUADA DE PROFESSORES DO ENSINO PROFISSIONAL TECNOLÓGICO E SUPERIOR
} TECHNOLOGICAL AND HIGHER EDUCATION

Rosimari de Fatima Cubas Blaka ${ }^{* *}$; Andreia de Bem Machado ${ }^{2}$ (1)

\section{Resumo}

0 presente artigo consiste em um relato de experiência da prática docente, realizado por meio de ações desenvolvidas no Programa de Formação Continuada de professores da Escola Técnica e Faculdade DAMA, situada no município de Canoinhas, Santa Catarina. 0 objetivo deste trabalho foi analisar as estratégias de ensino, baseada nas metodologias ativas, utilizadas na Formação Continuada dos professores da IE DAMA, no primeiro semestre letivo de 2021. A abordagem será realizada por meio de exemplos de atividades desenvolvidas com os professores durante os encontros de Formação. E para obtenção do feedback sobre a participação durante as formações pedagógicas, realizou-se pesquisa utilizando o método qualitativo com o alcance de relatos dos professores que participaram efetivamente do Programa. A coleta das informações e relatos foram realizadas através do uso das metodologias ativas, questionário, via Google Forms. Mediante a tabulação dos resultados do total de 32 professores participantes da pesquisa, $87,5 \%$ destacaram que utilizam frequentemente as Metodologias ativas praticadas durante os encontros, em suas aulas. Contudo, 65,6\% dos professores entrevistados solicitaram a continuidade das Formações que apresentem as Metodologias ativas com treinamentos periódicos. Morán (2015), Barbosa e Moura (2013), Berbel (2011); e Oliveira (2017), embasaram as discussões da temática, como processos inovadores do ensino-aprendizagem. A conclusão dessa experiência é que houve avanços no planejamento didático dos professores e está havendo inclusão das Metodologias ativas nas práticas docentes de forma frequente. Entretanto, ainda há desafios destacados pelos mesmos, para implementação das estratégias de ensino que podem ser superados com a continuidade das Formações com foco nas estratégias ativas e participativas.

\section{Abstract}

The present article consists in an experience report of teaching practice, accomplished through developped actions in a teachers Continiuing Education Program in an Technical School and Faculty DAMA, located in Canoinhas town, Santa Catarina. The goal this work was analysed the strategies based the active methodologies used in a teachers Continiuing Education Program in the IE DAMA in first semestre 2021. The approach will be accomplished through activities examples developped with the teachers during teachers meeting. And to get feedback about the participation during pedagogical training, a research was carried out using the qualitative method with the range of reports from teachers who effectively participated in the Program. The collection of information and reports were carried out through the use of active methodologies, questionnaire, via Google Forms. Through the tabulation of the results of the total 32 teachers participating in the research, $87.5 \%$ highlighted that they frequently use the active methodologies practiced during the meetings, in their classes. However, $65.6 \%$ of the interviewed teachers requested the continuity of training courses that present active methodologies with periodic training. Morán (2015), Barbosa and Moura (2013), Berbel (2011); and Oliveira (2017), supported the discussions on the
1 Mestre em Desenvolvimento Regional; Licenciatura em Pedagogia

* rosimaricubas@yahoo.com.br

2 Doutora em Engenharia e Gestão do Conhecimento; Licenciatura em Pedagogia

andreia.bem@ifsc.edu.br

Palavras-chave: Prática docente. Metodologias ativas. Ensinoaprendizagem.

theme, as innovative teaching-learning processes. The conclusion of this experience is that there have been advances in the didactic planning of teachers and there is frequent inclusion of active methodologies in teaching practices. However, there are still challenges highlighted by them, for the implementation of teaching strategies that can be overcome with the continuity of training focused on active and participatory strategies.

Keywords: Teaching practices. Active methodologies. Teaching-learning.

Recebido em: 16 Oct. 2021

Aceito em: 25 Nov. 2021

Publicado em: 30 Dez. 2021

(c) Copyright 2021

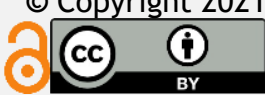

BLAKA, R. de F. C. 


\section{Resumen}

Este artículo consiste en un relato de experiencia de la práctica docente, realizada a través de acciones desarrolladas en el Programa de Educación Continuada para docentes de la Escola Técnica y Faculdade DAMA, ubicada en la ciudad de Canoinhas, Santa Catarina. El objetivo de este trabajo fue analizar las estrategias de enseñanza, basadas en metodologías activas, utilizadas en la Formación Continuada de los docentes del IE DAMA, en el primer semestre de 2021. El abordaje se llevará a cabo a través de ejemplos de actividades desarrolladas con los docentes durante los encuentros de entrenamiento. $\mathrm{Y}$ para obtener retroalimentación sobre la participación durante la formación pedagógica, se realizó una investigación utilizando el método cualitativo con el abanico de informes de los docentes que efectivamente participaron en el Programa. La recolección de información y reportes se realizó mediante el uso de metodologías activas, cuestionario, vía Google Forms. Al tabular los resultados del total de 32 profesores participantes en la investigación, el $87,5 \%$ destacó que utilizan con frecuencia las metodologías activas practicadas durante las reuniones, en sus clases. Sin embargo, el $65,6 \%$ de los docentes entrevistados solicitó la continuidad de cursos de formación que presenten metodologías activas con formación periódica. Morán (2015), Barbosa y Moura (2013), Berbel (2011); y Oliveira (2017), basaron las discusiones en el tema, como procesos innovadores de enseñanza-aprendizaje. La conclusión de esta experiencia es que ha habido avances en la planificación didáctica de los docentes y es frecuente la inclusión de metodologías activas en las prácticas docentes. Sin embargo, aún existen desafíos destacados por ellos, para la implementación de estrategias de enseñanza que se pueden superar con la continuidad de la formación enfocada en estrategias activas y participativas.

Palavras-chave: Práctica docente. Metodologías activas. Enseñanza-aprendizaje. 


\section{Introdução}

A s alterações conjunturais em âmbito social, político e econômico pela qual a sociedade vem passando nos últimos anos, apontam responsabilidades de novas competências e (re)estruturações nos sistemas educacionais em todos os níveis e modalidades de ensino.

Entre as mudanças necessárias estão as práticas pedagógicas desenvolvidas pelos professores no contexto educacional, consideradas preocupações constantes dos gestores e suas equipes de trabalho.

Diante desses desafios da contemporaneidade, que coloca em pauta as metodologias de ensino e aprendizagem como potencial para inovação na educação, a Instituição de Ensino Técnico e Superior DAMA, localizada em Canoinhas/SC, vem investindo em curso de Formação Continuada para seu quadro de professores e equipe pedagógica, focando nas diferentes práticas de ensino, contextualizadas com as metodologias ativas.

A atuação da referida formação ocorreu de forma geral para todos os professores atuantes nos cursos Técnicos Profissionalizantes em nível Pós-médio, subsequente, e Graduação, ofertados nas diferentes áreas de ensino: Saúde, Gestão e Indústria na IE DAMA.

O que se busca com esse Programa de Formação Continuada é preparar os professores com novos conhecimentos pedagógicos, com planejamento de estratégias centradas na participação efetiva dos estudantes e na construção do processo de ensinoaprendizagem, de forma flexível, interligada e híbrida, como salienta Morán (2015), ao se referir as metodologias ativas.

Nessa perspectiva a IE DAMA propõe um ambiente acolhedor e significativo, promovendo momentos de interação e colaboração entre os professores durante as Formações Continuadas.

A metodologia utilizada durante os encontros de formação dos professores da IE DAMA, teve início no dia 28/01/2021 a 23/07/2021, contemplando atividades síncronas e assíncronas. E o objetivo é estimular os 48 (quarenta e oito) professores atuantes na Instituição de Ensino, a utilizarem as Metodologias ativas com diferentes estratégias de ensino-aprendizagem em suas práticas docentes diárias.

Diante desse cenário, este estudo teve como objetivo geral analisar as estratégias de ensino, baseada nas metodologias ativas, utilizadas na Formação Continuada dos professores da IE DAMA Canoinhas/SC.

Mediante a atuação nesse contexto e consciente da importância da aprendizagem significativa, baseada em conhecimentos integrados e inovadores que proporcionem ao discente a valorização dos seus saberes prévios, os objetivos específicos serão norteados por: a) identificar as Metodologias ativas utilizadas na formação continuada dos professores na IES DAMA; b) analisar o uso das Metodologias ativas nas aulas dos cursos técnicos e de graduação; c) averiguar de que modo o uso das Metodologias ativas contribuem para a melhoria do ensinoaprendizagem.

O desenvolvimento da Formação Continuada, centrou-se na proposta de que os professores participantes, despertassem atitudes e valores, de forma que suas atividades pedagógicas sejam contextualizadas com as Unidades Curriculares e com o perfil da turma em formação. Dessa forma, justifica-se a relevância deste relato de experiências práticas, com amostragem de resultados que contemplam a utilização de Metodologias ativas e participativas na Educação Técnica e Superior DAMA.

Contudo, considerando as diversas Metodologias ativas existentes que podem ser desenvolvidas no contexto educacional, busca-se respostas para o problema da pesquisa: qual foi a percepção dos professores em relação ao uso das metodologias ativas e participativas utilizadas na Formação Continuada da IES DAMA - Canoinhas/SC.

Os desafios podem estar relacionados aos aspectos de alterações sociais e econômicas, avanços tecnológicos, processo produtivo, o mundo do trabalho e a formação inicial e continuada do professor para atuar na Educação Profissional e Superior. E os recursos estão ligados aos espaços pedagógicos de formação do sujeito, do trabalhador e do ser humano atuante na sociedade.

\section{METODOLOGIAS ATIVAS NA PRÁTICA DOCENTE}




\subsection{Metodologias ativas no ensino- aprendizagem}

A sociedade contemporânea apresenta-se cada vez mais competitiva pelo avanço na ciência e nas tecnologias com ampla abrangência na vida das pessoas, nos processos educacionais, sociais e no mundo do trabalho.

Dessa forma a educação e seu processo organizacional, deve se integrar como eixo principal na formação da população, propondo inovações em todos os setores, em especial, nas práticas pedagógicas utilizadas nos diferentes níveis e modalidades de ensino. E para que aconteçam tais inovações há necessidade de atualização profissional do corpo docente e consequentemente, com a inserção de novas estratégias no processo de ensinoaprendizagem que se adaptem às necessidades e expectativas dos acadêmicos, produzindo conhecimentos contextualizados com as demandas da sociedade atual.

Observa-se ainda, a educação como um direito de todos os cidadãos, como preconiza a Constituição Federal de 1988, no seu Art. 205. Nesse sentido, deverá ser promovida e incentivada a todas as pessoas, promovendo formação integral com atenção em todos os aspectos do desenvolvimento humano, para que atuem de forma plena no exercício da cidadania.

O direito à educação refere-se intrinsecamente a formação da sociedade, com ações educacionais inovadoras, empreendedoras e que desenvolvam competências e habilidades diferenciadas, proporcionando a elevação intelectual da população e consequentemente melhoria nos serviços prestados à sociedade.

Essa proposta foi estudada para a educação do Século XXI, e encontra-se registrada no Relatório da Organização das Nações Unidas para a Educação, a Ciência, a Cultura (UNESCO), desenvolvido pela Comissão Internacional sobre Educação, coordenada por Jacques Delors (1999), que descreve os desafios a serem superados e desenvolvidos pela educação com objetivo, de formar o cidadão integralmente. Aprender a conhecer; aprender a fazer; aprender a viver; e aprender a ser. São quatro pilares que se complementam para o desenvolvimento de competências, habilidades e valores essenciais na formação do aluno para todos os tempos e espaços do mundo globalizado, com compreensão do que o cerca, desenvolvendo comportamentos de responsabilidade com ética, igualdade e justiça, numa perspectiva de formação integral do ser humano.

Dessa forma exige-se do professor um novo perfil profissional, para mediar e construir conhecimentos, atingindo as expectativas dos educandos e da sociedade contemporânea.

0 ato de ressignificar o conhecimento, valorizando os saberes já construídos pelos alunos, amparandose numa postura reflexiva, investigativa e crítica diante do ensino-aprendizagem são propostas das novas estratégias pedagógicas, conceituado por Morán (2015), ao se referir as "Metodologias ativas como estratégias de ensino centradas na participação efetiva dos estudantes". Nessa concepção há construção do processo de ensinar e aprender, de forma flexível, interligada e híbrida.

As Metodologias ativas estão interligadas ao mundo conectado e digital e expressam-se por meio de modelos de ensino híbridos, com atividades síncronas e assíncronas com possibilidades de combinações educacionais.

Nesse mesmo enforque, Morán (2015), apud (ALMEIDA; VALENTE, 2012); destaca que o acesso à internet possibilita ao professor utilizar novas ferramentas de trabalho e disponibilizar novos conhecimentos. 0 uso das tecnologias educacionais torna as aulas ativas com obtenção de feedback em tempo real da participação e desempenho dos alunos. Contudo, ainda é complexo para alguns professores a utilização efetiva desses meios de informação, mesmo fazendo parte de uma sociedade altamente conectada.

Comarella, Mello (2018), relatam que os especialistas que participaram da elaboração do relatório NMC Horizon Report (2017), concordam que as tecnologias são relevantes para o planejamento e para as decisões na área da educação. Entretanto, os critérios para a escolha dos meios tecnológicos e digitais adequados a serem utilizadas no contexto do ensino-aprendizagem são fatores relevantes para o bom desenvolvimento da criatividade nos processos educacionais.

Os Ambiente virtuais de ensino-aprendizagem (AVEA) ou sistemas de gerenciamento de aprendizagem 
(Learning Management Systems - LMS), se incluem em uma categoria de softwares e aplicativos da web que possibilitam o desenvolvimento de Metodologias ativas e participativas com facilidades de acesso para os professores e alunos.

Nesse contexto Barbosa e Moura (2013), destacam as Metodologias ativas como métodos onde o professor deixa de ser o transmissor do conhecimento para ser o mediador da aprendizagem do aluno.

Berbel (2011), aponta ainda, que as Metodologias ativas se baseiam em formas de desenvolver o processo de aprender, utilizando experiências reais ou simuladas, visando diversas condições de solucionar, com sucesso, os desafios advindos das atividades essenciais da prática social em diferentes contextos.

O desenvolvimento do ensino-aprendizagem passa por vários processos, partindo do planejamento do professor, observação do currículo a ser trabalho, avaliação constante das atividades e o interesse e expectativas dos alunos em relação a sua formação. Dessa forma as Metodologias Ativas funcionam como introdutoras de novas potencialidades no processo de ensino e aprendizagem, tornando-o mais profícuo, dinâmico e significativo, favorecendo o diálogo e observação da realidade do aluno (OGAWA, 2020).

Nesse mesmo enfoque Berbel (2011), salienta que a aprendizagem significativa, partindo dos problemas ou situações problemáticas do dia a dia, necessita de ações didáticas de aprender fazendo (learning by doing). Esse conceito está baseado em Dewey (1859 -1952). Filósofo, psicólogo e pedagogo norteamericano, que teve grande influência sobre a pedagogia contemporânea. Formulou um ideal pedagógico (da Escola Nova) de que a aprendizagem ocorresse pela ação, aprender-fazendo.

A proposta de construir o conhecimento com a ação pedagógica "aprender fazendo" é um processo histórico, como se pode observar. E ainda, é o que se propõe na educação contemporânea, correlacionado aos pilares da educação para o século XXI.

Para Nóvoa (2017), a escola é o lugar de formação para seus profissionais. Não possui apenas um papel de transmissão do conhecimento, mas também um papel de laboratório de pesquisa e de produtora do conhecimento entre todos os envolvidos no processo educacional. Nessa mesma perspectiva, o mesmo autor, Nóvoa (2017), salienta a importância dos esforços do professor em criar um novo ambiente escolar, um ambiente de aprendizagem vivo e estimulante, de trabalho em comum sobre o conhecimento, um ambiente de curiosidade científica e de participação.

Nesse sentido é salutar que o professor compreenda que ensinar não representa o ato de reprodução do conhecimento historicamente acumulado. Mas sim um contínuo processo de (re)construção do conhecimento, e que este, seja aplicável à sociedade contemporânea.

E como descreve Oliveira (2017), a inserção das Metodologias ativas no processo ensinoaprendizagem possibilita que 0 aluno se sinta motivado e mantenha-se ativo durante as aulas, ação necessária para a aprendizagem prazerosa e significativa.

Nesse sentido o objetivo do desenvolvimento das metodologias ativas, seja em forma de projetos, programas com o uso das tecnologias digitais e/ou nas mais variadas formas existentes, facilitam o processo de ensino-aprendizagem, tornando o aluno protagonista de sua aprendizagem de forma espontânea, fazendo conexão com suas perspectivas educacionais. Pois apresentam-se como estratégias que permitem uma leitura e intervenção consistente sobre a realidade, bem como a valorização de diversos sujeitos no processo de construção coletiva, concebendo ao estudante sua participação de forma interativa com o contexto de atuação profissional, referindo-se em especial a Educação Profissional Tecnológica e Superior, foco dessa temática de estudo.

\subsection{Atividades docentes realizadas: Formação Continuada dos Professores}

A abordagem deste estudo está relacionada com o Programa de Formação Continuada dos professores que atuam em nível Pós-médio Profissional Tecnológico e Superior da Instituição de Ensino DAMA, realizada no primeiro semestre letivo de 2021.

O objetivo da formação é fornecer aos professores conhecimentos pedagógicos, com planejamento de 
estratégias de ensino-aprendizagem que valorize 0 aluno de acordo com suas experiências e expectativas, oportunizando a sua participação de forma colaborativa durante o percurso formativo.

O Programa foi direcionado pela equipe pedagógica da IE DAMA (Coordenadores e Orientadores Pedagógicos e de cursos), e abordou os elementos essenciais que envolvem ações didáticaspedagógicas, tais como: planejamento - que inclui a seleção dos objetivos educacionais e dos "saberes" (sejam eles técnicas, conceitos, contextos); a escolha das melhores estratégias de ensino para promover a aprendizagem. Refletindo sobre aqueles a quem queremos ensinar. A mediação docente - realizada por momentos do ensino efetivo, integrando a comunicação, orientação dos estudantes, motivação e acompanhamento do seu percurso formativo. E a avaliação - como processo educativo, que possui diversas funções, desde o diagnóstico, a motivação e os conhecimentos prévios dos estudantes. Orientando o processo de ensino na direção mais adequada possível ou ainda, direcionando o estudante para uma etapa futura de aprendizagem.

As sugestões de estratégias de ensino com abordagens de Metodologias ativas, utilizadas durante as formações dos professores, tiveram embasamento teórico e prático obtidos por meio dos materiais e webconferências disponibilizados no Curso de Pós-Graduação em Docência para a Educação Profissional'1.

E como aporte didático-pedagógico foi elaborado um material didático, denominado de "Práticas pedagógicas interdisciplinares para a educação profissional", contendo modelos de Metodologias ativas e participativas e as formas de aplicação durante a prática docente, adaptáveis aos cursos ofertados pela IE. DAMA, contendo: aprendizagem por obras; aprendizagem por projeto; aprendizagem por simulação; aprendizagem por imersão e visita técnica; aprendizagem por análise de erro deliberado; aprendizagem tecnográfica ou análise da atividade; aprendizagem com a realização de perícia; aprendizagem - estudo de caso; aprendizagem por resolução de problemas; aprendizagem por experimento e experiência; aprendizagem por experimento de laboratório; avaliação pelos pares de erros deliberados; aula estruturada no formato de perguntas; análise e explicação de modelos; piloto e navegador; métodos de movimento completo ; instrução entre pares (peer instruction - pi); arco de Maguerez, e estratégias de ensino na sala de aula - sala de aula invertida, de modo síncronas e assíncronas, com interação e mecanismos tecnológicos e virtuais. Esse material foi compartilhado para todos os professores de forma online, utilizando as metodologias ativas, aplicativo canva.com e por meio do código de QR code.

Para implementar o processo metodológico a $\mathrm{IE}$ DAMA, conta ainda com plataforma online que possibilita aos acadêmicos, acesso aos laboratórios virtuais, biblioteca online, vídeos de apoio, conteúdo complementar entre outros mecanismos pedagógicos que facilitam o desenvolvimento de Metodologias ativas, integrando os conhecimentos da teoria aliando a prática profissional.

De acordo com o Projeto Pedagógico da Instituição de Ensino DAMA (PDI), a forma de desenvolvimento metodológico das unidades curriculares, dividem-se em: metodologias de ensino com aulas teóricas expositivas e dialogadas (40\%); Aulas práticas/simuladas em ambiente profissional, laboratórios físicos e in sílico (virtuais), (40\%); e Aulas com Metodologia de Aprendizagem ativa - Sala de Aula Invertida (20\%), online. O que justifica a inserção das Metodologias ativas nas práticas docentes.

Para o relato das experiências, elegeu-se 04 metodologias ativas aplicadas, durante a realização dos encontros de Formação Continuada com uso de aplicativos on-line em tempo real nas plataformas gratuitas: Kahoot, Plickers e Mentimeter e de grupo.

Com o aplicativo Kahoot, foram realizados jogos rápidos interativos, utilizando questões das disciplinas curriculares dos cursos, demonstrando aos professores as várias possibilidades de utilização do aplicativo nas práticas docentes.

Essas atividades interativas variam desde promover um quiz durante a aula (presencial ou remota) para

\footnotetext{
1 Curso de Pós-Graduação em Docência para a Educação Profissional [em andamento] - plataforma Moodle EaD IFSC, 2020/2021. Instituto Federal de Santa Catarina - IFSC.
} 
identificar se os alunos estão entendendo a matéria, até mesmo criar momentos de debate com a turma.

De acordo com a explanação do professor e engenheiro Angelo Battistini (2021) esta ferramenta tecnológica pode ser usada para desenvolver competições entre grupos e fazer avaliações interativas.

Para apresentar o aplicativo Plickers e suas formas de uso na sala de aula, foi simulado questões em forma de testes, utilizando os conteúdos das unidades curriculares dos cursos como exemplos. Dessa forma os professores participaram da experiência, esclarecendo dúvidas sobre o uso da ferramenta.

De acordo com Nunes e Couto (2019, p. 60) “O aplicativo Plickers é uma proposta inovadora de avaliação. Tem como finalidade precípua, favorecer uma avaliação dinâmica, que permita mensurar instantaneamente, o nível de aprendizado". Nesta proposta possibilita ao professor gerar relatório ao final de cada questão, análise acerca do aprendizado sobre cada ponto estudado, promovendo, se necessário, uma revisão direcionada ao tema que apresentou baixo rendimento.

Com o aplicativo mentimeter.com foi criado Nuvem de Palavras, gráficos com múltipla escola, entre outros. Esta ferramenta foi utilizada para destacar o ponto de vista dos professores num processo de avaliação diagnóstica, identificando os seus conhecimentos e percepções a respeito de duas práticas docentes, apontando desafios existentes. (EX: conceitos de verificação e avaliação do processo de ensino-aprendizagem; e os desafios para inovar a educação e melhorar as práticas pedagógicas diárias).

De acordo com a pesquisa de Santos et al (2021, p.98) "O aplicativo Mentimeter possibilita criar apresentações interativas em tempo real". Ocorrendo interação entre os professores, com apresentação do feedback sobre a compreensão dos professores nos determinados assuntos abordados, favorecendo reflexões sobre as questões citadas, num processo de discussão sobre as práticas e os desafios que ocorrem diariamente nas turmas

\footnotetext{
${ }^{2}$ Resolução do CNE $n^{\circ} 7$ de 18 de dezembro de 2018, que propõe $10 \%$ da carga horária curricular com atividades de extensão.
}

heterogêneas, devido os diversos perfis dos alunos existentes, com diversidades culturais, sociais, faixa etária e de aprendizagem.

A atividade realizada com os professores, demonstrou as possibilidades de uso da ferramenta: enquetes, nuvens de palavras ou coleta de perguntas, ambas com o intuito de promover um ensino ativo e sistemático, com foco centrado no aluno.

Esses aplicativos possibilitaram interação entre os formadores e os professores participantes de forma positiva.

Posteriormente de forma interativa, numa proposta de formação-ação, utilizando o laboratório de informática da IE DAMA, os professores criaram suas contas nos aplicativos on-line (Kahoot, Plickers e Mentimeter.com), simulando atividades pedagógicas para aplicação em sala de aula. Pois de acordo Moran (2004, p. 348) apud (PERRENOUD, 2000, p.139) “As novas tecnologias reforçam a contribuição dos trabalhos pedagógicos e didáticos contemporâneos, pois permitem que sejam criadas situações de aprendizagens ricas, complexas, diversificadas". Dessa forma, na prática docente há maior confiança do professor em aplicar posteriormente em suas aulas.

Para abordar as atividades de extensão curricular. A formação baseou-se na obrigatoriedade da curricularização da extensão, Resolução do CNE $\mathrm{n}^{\circ}$ $7 / 2018^{2}$, que propõe atividades de extensão curricular.

Para a realização dessa atividade, utilizou-se a metodologia ativa - Arco de Maguerez, com simulação de um projeto para o atendimento às demandas da comunidade local, denominado: “Conhecendo o Bairro Campo D' Água Verde Canoinhas/SC e produzindo cuidados de Enfermagem".

De acordo com Gemignani (2012), a metodologia do Arco de Maguerez, divide-se em cinco etapas: observação da realidade (problema); pontos-chave; teorização; hipóteses de solução; e as propostas de

Estabelece as Diretrizes para a Extensão na Educação Superior Brasileira e regulamenta o disposto na Meta 12.7 da Lei $\mathrm{n}^{\circ}$ 13.005/2014 que aprova o Plano Nacional de Educação. 
aplicação à realidade (prática), de acordo com a Figura 1.

Figura 1 - Descrição das etapas do Arco de Maguerez

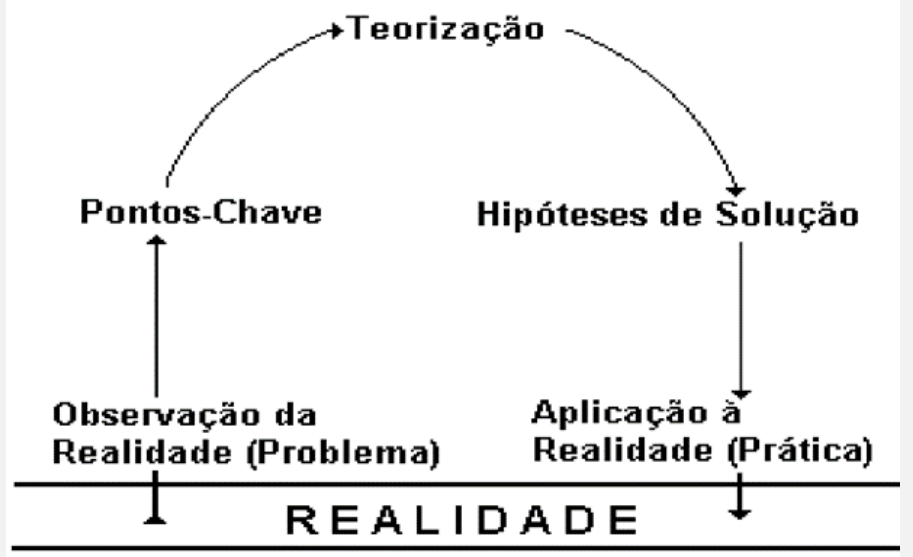

Fonte: Gemignani (2012)

Dessa forma os professores reuniram-se em equipes e simularam atividades teóricas e práticas para serem desenvolvidas com os alunos. O objetivo dessa formação-ação foi familiarizar os professores de como introduzir a metodologia em sua prática pedagógica, observando a realidade local e com base na interdisciplinaridade do curso, propor aos alunos a elaboração de Projetos de extensão que possam ser desenvolvidos nas comunidades locais, fazendo a indissociabilidade educacional entre: ensino, pesquisa e extensão.

De acordo com Gemignani (2012). O desenvolvimento do Método do Arco de Charles Maguerez, centra-se na realidade do indivíduo, suas vivências e experiências, seus saberes e conhecimentos prévios, parte-se sempre da realidade do aluno, buscando problemas reais e que, apresente expectativas e necessidades de resolução.

O objetivo da extensão curricular é integrar o aluno na aprendizagem colaborativa, com ações interativas, direcionada pelo trabalho conjunto entre os estudantes e educadores, baseada na perspectiva de que a aprendizagem é um construto social com intervenções educacionais.

\subsection{Avaliação do Programa de Formação continuada dos professores - 2021/1}

Para avaliar a eficiência da utilização das Metodologias ativas, realizadas durante os encontros de Formação Continuada, bem como a aplicabilidade nas práticas docentes, foi realizada na primeira quinzena do mês de agosto de 2021, uma pesquisa com os professores atuantes na IE DAMA.

Dessa forma foi enviado aos professores um formulário via Google Formulários para preenchimento, mediante Termo de consentimento livre e esclarecido - TCLE. Dentre as questões abordadas, os pontos observados para esse relato foram: periodicidade de utilização das Metodologias ativas e participativas em suas aulas e suas formas de aplicação; os desafios para implementação das Metodologias ativas na prática diária docente; e a compreensão sobre a importância da utilização das metodologias participativas e ativas na prática docente, com destaque de algumas observações e relatos sobre as Metodologias ativas realizadas com os alunos em sala de aula.

Mediante análise dos resultados da pesquisa qualitativa e quantitativa, observa-se a participação de 32 professores, $(66,6 \%)$ do corpo docente da IE DAMA.

$\mathrm{Na}$ primeira questão apresenta-se os resultados sobre a periodicidade de utilização das Metodologias ativas, apresentadas durante os encontros de Formação Continuada, e que estão sendo aplicadas nas práticas docentes. Nessa questão observa-se a relevância na utilização, sendo que 28 (87,5\%) dos professores entrevistados responderam que utilizam com frequência em suas aulas; $3(9,4 \%)$ utilizam raramente e somente $1(3,1 \%)$ não utilizou, ainda, as Metodologias ativas em suas aulas, como pode-se observar na disposição do Gráfico 1,

Gráfico 1: Periodicidade de utilização das Metodologias ativas durante as aulas 


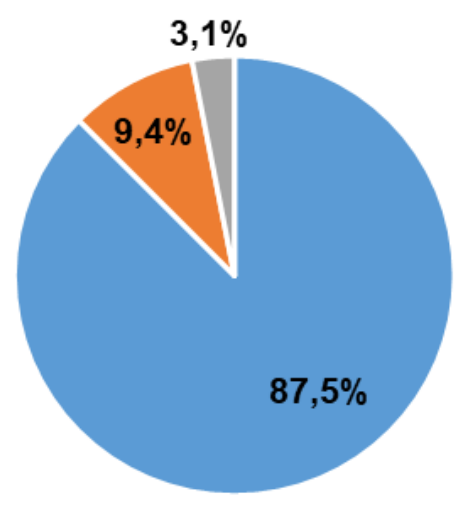

- Frequentemente $\quad$ Raramente $\quad$ Não utilizo

Fonte: Elaborado pelas autoras no Google Forms/2021.

Pode-se compreender que a utilização com frequência das Metodologias ativas pelos professores, constatado no percentual de $87,5 \%$, durante o processo de ensino-aprendizagem, é atribuída pelas práticas realizadas e incentivo durante os encontros de Formação Continuada. Também devido ao modelo de organização para elaboração dos planos de ensino adotado pela IE DAMA, exposto anteriormente. Outra especificidade da Instituição é o acompanhamento e apoio direcionado aos professores é realizado permanentemente pela equipe pedagógica e coordenadores de cursos para efetivação do processo de ensino-aprendizagem.

$\mathrm{Na}$ questão seguinte, pode-se observar no Gráfico 2, os resultados do questionamento aos professores sobre as formas e em quais espaços educacionais foram utilizados as metodologias ativas.

Gráfico 2: Formas e espaços educacionais de utilização das Metodologias ativas.

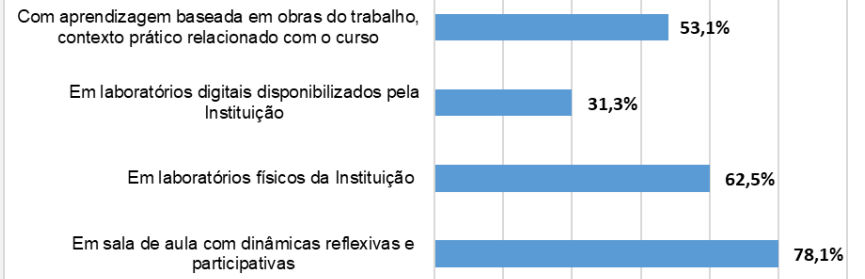

Fonte: Elaborado pela autora no Google Forms/2021.
Nesta questão, os professores assinalaram mais de uma alternativa, apontando os diferentes espaços de ensino-aprendizado que utilizaram. E como pode-se observar, a maioria das respostas, ou seja $78,1 \%$, utilizaram nas atividades ativas e participativas em sala de aula. Contudo, pode-se atribuir essa resposta a disponibilização do documento elaborado "Práticas pedagógicas interdisciplinares para a educação profissional", bem como os aplicativos online. Os modelos de atividades que foram apresentados e testados com os professores durante os encontros presenciais e online (Kahoot, Plickers e Mentimeter.com), havendo incentivo para que apliquem de forma prática, utilizem os laboratórios disponíveis, (físicos e virtuais) e as dinâmicas que podem ser utilizadas com os determinados cursos em desenvolvimento, saúde, gestão e indústria. Nessa questão a abordagem das Metodologias ativas realizadas e simuladas com os professores durante os encontros, promoveram maior segurança e confiabilidade, para a utilização em seus planos de ensino.

Nessa questão, os resultados comprovam a teoria de Nóvoa (2017), ao se referir a relevância da utilização de espaços diferenciados de ensino-aprendizagem, proporcionando a curiosidade científica e de participação.

Contudo os resultados demonstram que foram utilizados em laboratórios físicos e digitais da IE DAMA, como também com aprendizagem baseada em obras, contextualizadas com os diferentes cursos Técnicos e superior de atuação dos professores.

$\mathrm{Na}$ terceira questão abordou-se os desafios para implementação das Metodologias ativas na prática docente, apresentando no Gráfico 3, os resultados.

Gráfico 3: Desafios para implementação das Metodologias ativas na prática docente.

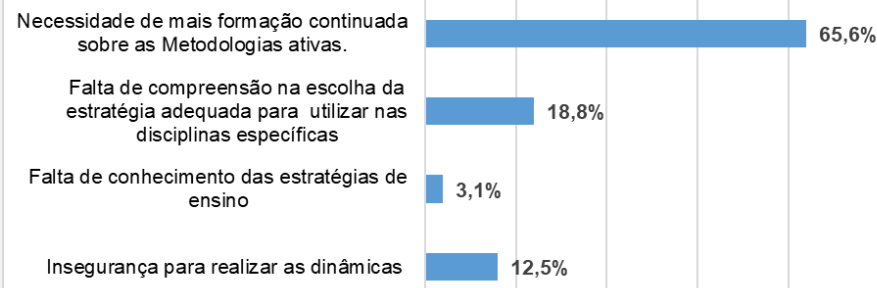

Fonte: Elaborado pela autora no Google Forms/2021. 
Os resultados demonstram com ênfase a necessidade de mais Formação com enfoque na aplicação das Metodologias ativas. 25, ou seja, $(65,6 \%)$ dos professores entrevistados solicitaram a continuidade das Formações que apresentem as Metodologias ativas com treinamentos periódicos. $6(18,8 \%)$, ainda, tem dúvidas para aplicação das metodologias nas diferentes temáticas abordadas no percurso formativo; e 4 professores 12,5\%, sentem-se inseguros para aplicar as diferentes estratégias de ensino. $E$ ainda, 1 professor, ou seja, $(3,1 \%)$ dos entrevistados não possui conhecimento para aplicar em suas aulas. A explicação para esse percentual, pode ser que esse professor não tenha participado de nenhum dos 05 encontros realizados no primeiro semestre letivo de 2021. Entretanto, foi importante participar da pesquisa para se inteirar das atividades realizadas na Formação Continuada.

Os resultados dos itens abordados, respondem à questão norteadora deste artigo, correlacionando a percepção dos professores e o uso das metodologias ativas e participativas utilizadas nos encontros da Formação Continuada da IES DAMA - Canoinhas/SC. Contudo, os desafios relacionados aos fatores centrados nos pilares para a educação do século XXI, de acordo com Jacques Delors (1999), aprender a "ser" completa a concepção da atuação docente. Ser professor exige além de sua formação acadêmica. Exige compromisso com sua função de mediar e oportunizar o conhecimento de forma significativa para o aluno.

A realidade da IE DAMA, de caráter privado, não contempla em seu quadro de professores a exclusividade de carga horária para docência. Os professores atuam durante o dia em outras áreas profissionais (saúde e indústria). Dessa forma seu tempo de planejamento e de formação para docência é reduzido.

Entretanto, o objetivo do Programa de Formação continuada da Instituição é proporcionar conhecimentos didático-pedagógicos para a realização das práticas docentes. Durante os encontros de Formação continuada, e no dia a dia de atuação pedagógica na El DAMA, as orientações são comuns e permanentes entre a equipe pedagógica e os professores.

Nesse sentido, embasa-se na concepção de Berbel (2011); Oliveira (2017), Ogawa (2020), entre outros que destacam as Metodologias ativas que possibilitam a aprendizagem significativa do aluno. Nesse mesmo contexto, a proposta é observar as dificuldades dos professores para aplicar ações práticas que incentivem ações de modo que os professores aprendam fazendo (learning by doing), tal qual os alunos em seu percurso formativo.

E para atingir o terceiro objetivo específico desta pesquisa, averiguou-se de que modo o uso das Metodologias ativas contribuem para a melhoria do ensino-aprendizagem. Como resposta dos professores que escreveram de forma sucinta, sua compreensão sobre a utilização das Metodologias ativas em suas práticas docentes, destacam-se alguns relatos sobre a temática abordada.

Quadro 1: Pesquisa realizada com os professores.

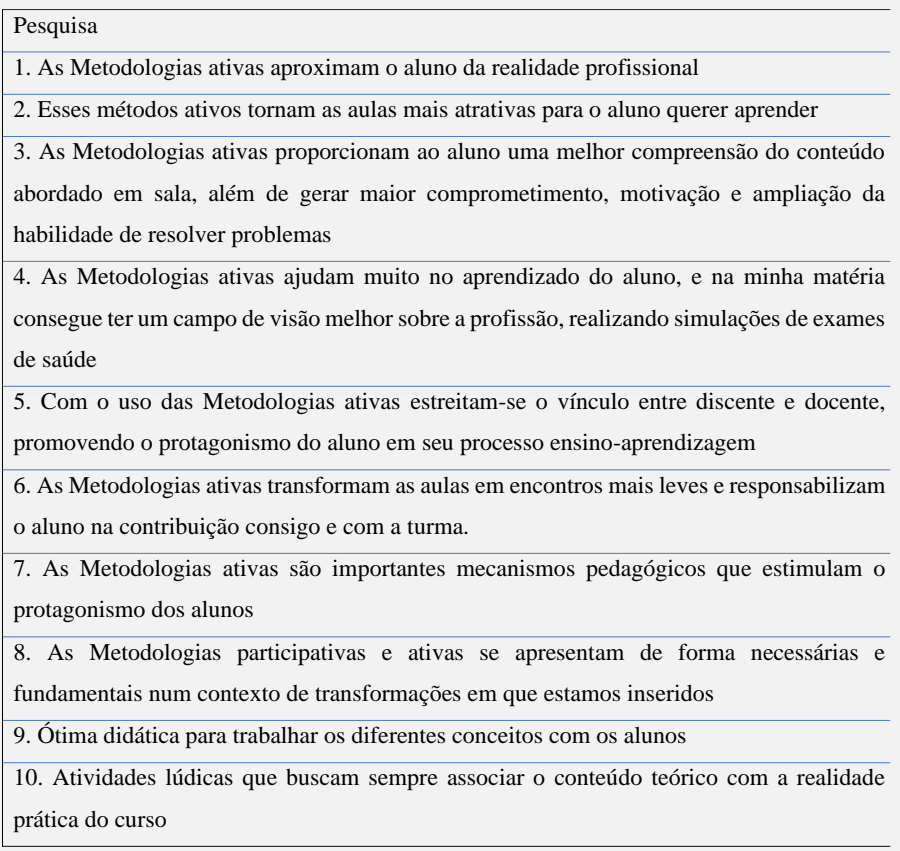

Fonte: Elaborado pelas autoras, 2021.

A compreensão dos professores em relação às Metodologias ativas é um caminho relevante para a mudança da postura docente. Esses conceitos formulados pelos professores demonstram a percepção e os resultados obtidos durante o processo de ensino-aprendizagem com a utilização das Metodologias ativas. Nesse sentido pode-se compreender como um processo formativo que buscam novos conhecimentos como salienta (BERBEL, 2011). 


\section{CONSIDERAÇÕES FINAIS}

A partir da experiência apresentada, e vivenciada durante a realização da Formação Continuada dos Professores, da qual faço parte como formadora da IES DAMA. Foi possível avaliar a relevância das atividades abordadas no Programa, especialmente as Metodologias ativas trabalhadas e praticadas durante os encontros. Teve-se boa adesão nas participações, contabilizando que, cerca de 24, ou seja, (50\%) do total de 48 professores da IE DAMA e participantes da Formação, atingiram, 100\% de frequência nos encontros, de acordo com as listas de presença analisadas no primeiro semestre letivo de 2021.

Os professores demonstraram-se interessados em aprender novas estratégias de ensino, e de acordo com a pesquisa realizada, estão utilizando em suas práticas docentes.

Dessa forma, compreende-se que as Metodologias ativas atuam como uma via de mão dupla, onde há interação constante entre o professor e o aluno. Contudo, ainda, há muitos desafios para implementar efetivamente as Metodologias ativas de forma integral no cotidiano educacional.

A participação efetiva dos professores no Programa de Formação continuada contribuiu de forma significativa para 0 processo de ensinoaprendizagem da Educação Profissional e Superior, facilitando a interação e a empatia entre professores e a equipe pedagógica, formando vínculos de confiabilidade para esclarecimentos de dúvidas e inserção de práticas inovadoras nas ações pedagógicas da prática docente diária.

Essa experiência vivenciada, promoveu uma visão ampla dos desafios que necessitam ser superados pelos educadores, na implementação das Metodologias ativas e novas estratégias de ensino no cotidiano da IE DAMA. E poderá servir como exemplo para outras Instituições de Ensino Profissional Tecnológico e Superior que buscam alternativas inovadoras nas ações docentes.

Dessa forma a meta é continuar realizando Formações continuadas, com ênfase nas dificuldades docentes. A abrangência se dará nas Metodologias ativas que podem ser utilizadas em diferentes contextos educacionais, buscando a qualidade do ensino-aprendizagem de forma orgânica, flexível, prazerosa e com significado para o aluno.

O objetivo é proporcionar melhorias no ensinoaprendizagem dos futuros profissionais, egressos dos cursos técnicos e de graduação, seja da área da saúde, indústria, gestão, entre outras áreas educacionais da sociedade contemporânea.

Propõe-se ainda, continuar avaliando a efetividade das Metodologias ativas como forma de construção do conhecimento no Ensino Técnico e Superior e com base nessa realidade, redimensionar os rumos do processo de ensino-aprendizagem de forma eficaz.

\section{REFERÊNCIAS}

BARBOSA, E. F. MOURA, D. G. Metodologias ativas de aprendizagem na Educação profissional e Tecnológica. B. Tec. Senac, Rio de Janeiro, v. 39, n.2, p.48-67, maio/ago. 2013.

BERBEL, Neusi Aparecida Navas. As metodologias ativas e a promoção da autonomia de estudantes. Revista Semina: Ciências Sociais e Humanas, Londrina, PR. v. 32, n. 1, p. 25-40, jan/jun. 2011. Disponível

em:

<http://www.uel.br/revistas/uel/index.php/semin asoc/article/view/10326/0>. Acesso em: 05 jul. 2021.

BRASIL. Constituição Federal (1988). Constituição da República Federativa do Brasil. Disponível em: <http://www2.camara.leg.br/legin/fed/consti/198 8/constituicao-1988-5-outubro-1988-322142-

publicacaooriginal-1-pl.html>. Acesso em: ago. 2021.

COMARELLA, Rafaela Lunardi; MELLO, Carlos Alberto da Silva. Inovações Educacionais e Tecnológicas para Educação. Florianópolis: publicação do IFSC, $2018 . \quad$ Disponível em: https://moodle.ead.ifsc.edu.br/mod/book/view.ph p?id=111749. Acesso em: 09 ago. 2021. [recurso digital].

DAMA. Instituição de Ensino Técnico e Superior. Projeto Pedagógico da Instituição de Ensino DAMA (PDI). Canoinhas, SC, 2021.

DELORS, Jacques (Coord.). Os quatro pilares da educação. In: Educação um tesouro a descobrir. 
UNESCO, MEC. São Paulo: Cortez, 1999. p. 89-102. (Relatório para a UNESCO da Comissão Internacional sobre educação para o século XXI).

GEMIGNANI, Elizabeth Yu Me Yut. Formação de Professores e Metodologias Ativas de EnsinoAprendizagem: Ensinar Para a Compreensão. Revista Fronteira da Educação [online], Recife, v. 1, n. 2, 2012. ISSN: 2237-9703. Disponível em: <http://www.fronteirasdaeducacao.org/index.php/ fronteiras/article/view/14>. Acesso em: 21 jun. 2021.

LOPES, Marina Lopes. Ferramenta passa a ter versão em português e, para te ajudar, trazemos sugestões de especialistas, respostas para dúvidas frequentes e um tutorial de como usar. Professor e engenheiro Ângelo Battistini, criador dos cursos online Kahoot. Disponível em: https://porvir.org/kahoot-comousar-para-deixar-suas-aulas-mais-divertidas/.

Acesso em 10 ago. 2021.

MEC. Ministério da Educação/Conselho Nacional de Educação/Câmara de Educação Superior. Resolução $N^{\circ} 7$, de 18 de dezembro de 2018. Estabelece as Diretrizes para a Extensão na Educação Superior Brasileira e regimenta o disposto na Meta 12.7 da Lei $n^{\circ} 13.005 / 2014$, que aprova o Plano Nacional de Educação - PNE 2014-2024 e daí outras providências. Diário Oficial da União. Publicado em: 19/12/2018 | Edição: 243 | Seção: 1 | Página: 49. Disponível em: https://www.in.gov.br/materia/-

/asset_publisher/Kujrw0TZC2Mb/content/id/55877 808. Acesso em: 21 jun.2021.

MORÁN, José. Mudando a educação com metodologias ativas. [Coleção Mídias Contemporâneas. Convergências Midiáticas, Educação e Cidadania: aproximações jovens. Vol. II] Carlos Alberto de Souza e Ofelia Elisa Torres Morales (orgs). PG: Foca Foto-PROEX/UEPG, 2015.
Disponível em: http: / /www2.eca.usp.br/moran/wpcontent/uploads/2013/12/mudando_moran.pdf. Acesso em: 10 ago. 2021.

A contribuição das tecnologias para uma educação inovadora . Contrapontos - volume 4 - n. 2 - p. 347-356 - Itajaí, maio/ago. 2004.

NóVOA, Antonio. A Escola do século XXI. Base Nacional Comum Curricular. Material para o professor - Por dentro da BNCC - Ed. Moderna; v . 4, p. 10-13, 2017.

NUNES, V. W. N; COUTO, R. R. B. Metodologias Ativas apoiadas por recursos digitais: usando os aplicativos Prezi e Plickers. In. Informática na educação e suas tecnologias [recurso eletrônico] / Organizador Ernane Rosa Martins. - Ponta Grossa, PR: Atena Editora, 2019. Informática na Educação e suas Tecnologias. Disponível em: https://www. atenaeditora.com.br/postartigo/26045. Acesso em 10 ago. 2021.

OGAWA, Mary Natsue. Didática do Ensino Superior. $1^{\text {a }}$ Ed. - Curitiba (PR) IESDE. (2020).

OLIVEIRA, Paulo Eduardo. Formação de Professores - Consultoria Educacional e Formação de Professores. Disponível em <http://profpaulooliveira.wixsite.com/consultoria> . Acesso: 10 jun. 2021.

SANTOS, Geovane Barbosa et al. As potencialidades do aplicativo Mentimeter para a construção de processos de ensino e aprendizagem interativos. In. Ferramentas digitais para o ensino de ciências da natureza. Bagé - RG. Faiht, 2021. Disponível em: https: / / www.researchgate.net/profile/LuanaJoras/publication/350240048. Acesso em 10 ago. 2021. 